\title{
Prevention of in-stent restenosis with endothelial progenitor cell (EPC) capture stent placement combined with regional EPC transplantation: An atherosclerotic rabbit model
}

\author{
You-Hua Huang ${ }^{1}$, Qiang Xu' ${ }^{1}$, Tao Shen ${ }^{1}$, Jian-Ke Li ${ }^{1}$, Jing-Yu Sheng ${ }^{2}$, Hong-Jian Shi ${ }^{1}$ \\ ${ }^{1}$ Department of Radiology, Wujin Hospital, Jiangsu University, Changzhou, China \\ ${ }^{2}$ Department of Cardiology, Wujin Hospital, Jiangsu University, Changzhou, China
}

\begin{abstract}
Background: Even with drug-eluting stents, the risk of in-stent restenosis (ISR) remains high. The goal of this study was to investigate the use of an endothelial progenitor cell (EPC) capture stent plus regional EPC transplantation to reduce the ISR rate.

Methods: Endothelial progenitor cell capture stents were fabricated using fibrin gel and anti-CD34 plus anti-VEGFR-2 dual antibodies. Twenty male New Zealand white rabbits established as an atherosclerotic model were randomly divided into two groups: group $1(n=10)$, in which EPC capture stents were deployed into the right iliac artery; and group $2(n=10)$, in which sirolimus-eluting stents were placed. In both groups, EPCs were transplanted into target vessels beyond the stents, with outflow blocked. Radiologic-pathologic correlation outcomes were reviewed after 2 months.

Results: The technical success rate of EPC capture stent placement plus EPC transplantation was $100 \%$. The ISR rate in group 1 was lower than in group 2 (1/10 vs. 4/10; $p>0.05)$. Minimal luminal diameters were larger in group 1 than in group 2 (computed tomographic angiography, $1.85 \pm 0.15 \mathrm{~mm}$ vs. $1.50 \pm 0.20 \mathrm{~mm}$; duplex ultrasound, $1.90 \pm 0.10 \mathrm{~mm}$ vs. $1.70 \pm 0.30 \mathrm{~mm} ; p>0.05)$. Transplanted EPCs were tracked positively only in group 1. Pathologic analysis demonstrated neointimal hyperplasia thickness of $0.21 \pm 0.09 \mathrm{~mm}$ in group 1 vs. $0.11 \pm 0.07 \mathrm{~mm}$ in group $2(p<0.05)$.

Conclusion: Endothelial progenitor cell capture stent placement plus local EPC transplant decreases the ISR rate through thrombosis reduction rather than through neointimal hyperplasia inhibition. (Cardiol J 2019; 26, 3: 283-291)
\end{abstract}

Key words: in-stent restenosis, thrombosis, endothelial progenitor cells, transplantation, drug-eluting stent

\section{Introduction}

Cardiovascular disease (CVD) remains the leading cause of morbidity and mortality in the Western world and developing countries. According to the American Heart Association statistics committee, CVD is responsible for higher costs than any other disease process [1].
With advances in quality of care, endovascular interventions have improved mortality rates among patients with CVD; however, in-stent restenosis (ISR) remains the greatest obstacle in coronary interventional treatment. Drug-eluting stents (DES) have been shown to dramatically reduce the rates of restenosis and target lesion revascularization when compared with bare-metal stents (BMS) in

Address for correspondence: Hong-Jian Shi, MD, PhD, Department of Radiology, The Affiliated Wujin Hospital, Jiangsu University, Changzhou, China, 213017, tel: +86 519 85579213, +8613776893070, fax: +86 51985325466 , e-mail: shihongjian@sina.com

Received: 8.05.2017 Accepted: 15.01.2018 
short- and mid-term studies [2-5]. However, as more complex cases have been included in this research, it has become apparent that the rate of ISR with DES is much higher than initial trials had revealed, with rates as high as $20 \%$; long-term results are especially dismal $[6,7]$.

In light of this, treatment of DES ISR has become a topic of interest for clinicians. For interventional cardiologists, the greatest dilemma may be how to treat a patient with DES ISR in the absence of any clear-cut guidelines. The modalities available for treatment of DES ISR include routine plain old balloon angioplasty, use of cutting or scoring balloons, use of drug-coated balloons or drug-eluting balloons, use of BMS, use of same DES or different DES, vascular brachytherapy, bypass surgery, use of stent-grafts, or laser atherectomy [8-15]. However, none of these modalities is optimal.

Treating these patients is difficult in part because the mechanisms of ISR and delayed ISR with DES have not been fully investigated. Some studies have suggested that the underlying mechanism of ISR is related to incomplete stent endothelialization [3, 9-11]. If rapid re-endothelialization occurs, the lining of the stent provides a nonthrombogenic surface, interrupting cytokine-driven activation of smooth muscle cells (SMCs) in vascular tissues and accelerating normal wound healing; in this way, late-stage ISR can be alleviated [16]. Thus, cell therapy appears to be an appealing option in these patients. Several studies (mostly experimental animal studies) have evaluated this rapid re-endothelialization strategy by stent strut recruitment of circulation endothelial progenitor cells (EPCs). These studies demonstrated the positive role of enhanced endothelial regeneration in inhibiting acute thrombosis and excessive inflammatory response, facilitating the recovery process, and successfully minimizing severe pseudointimal hyperplasia [17-22]. However, a commercially available EPC capture stent (Genous Bio-engineered R stent, OrbusNeich Medical, Fort Lauderdale, Florida, USA) has not demonstrated the ability to reduce neointimal hyperplasia as the designers had expected. The HEALING trials, which assessed the Genous R stent, demonstrated only slight improvements in rapid re-endothelialized intima formation and the need for short-term dual antiplatelet therapy after stent placement; this stent was also found to be noninferior to DES with respect to target lesion revascularization and rate of major adverse cardiac events [23-26].

This study therefore sought to investigate the feasibility of using a dual antibody-coated
EPC capture stent enhanced with regional EPC transplantation to reduce the rate of ISR through rapid re-endothelialization in an atherosclerotic animal model. This study also sought to address the controversy regarding whether rapid re-endothelialization inhibits neointimal hyperplasia in the setting of ISR.

\section{Methods}

This study was carried out in accordance with recommendations from the Guide for the Care and Use of Laboratory Animals from the National Institutes of Health. The Institutional Animal Care and Use Committee of Jiangsu University approved the study.

\section{EPC culture}

Endothelial progenitor cells were isolated from newly drawn male New Zealand white rabbit (Jingling Farm Center for Animal Experiments, Nanjing, China) peripheral blood via the density gradient centrifuge method. Methods for EPC isolation, culture, and characterization have been described previously [27]. Briefly, secondgeneration EPCs were harvested on day 12. The phenotypes of CD34, VEGFR-2, and vWF were positively expressed by these cells. The presence of up-taken DiI-Ac-LDL and binding FITC-UEA-1 was confirmed by inverted fluorescence microscopy, indicating that these cells were functional EPCs (Fig. 1).

\section{In vitro dual antibody-coated stent fabrication}

Ten nitinol balloon-expandable $3.0 \mathrm{~mm} \times 15 \mathrm{~mm}$ 316L stainless steel open-cell design Sun BMS (SINO Medical Sciences Technology Inc, Tianjin, China) were immersed in fibronectin solution $(100 \mu \mathrm{g} / \mathrm{mL}$; Gene Operation, Ann Arbor, USA) and incubated at $37^{\circ} \mathrm{C}$ in $5 \% \mathrm{CO}_{2}$ for $24 \mathrm{~h}$. Coated rabbit anti-rabbit CD34 (Bioss, Beijing Biosynthesis Biotechnology Co., Ltd, Beijing, China) and antirabbit VEGFR-2 (Bioss) stents were constructed in a wet-to-dry lyophilized fashion by bathing the stent in the dual-antibody solution $(100 \mu \mathrm{g} / \mathrm{mL})$ for $1 \mathrm{~min}$ and then using a hair dryer to blow dry the stent for $1 \mathrm{~min}$, thus increasing antibody adhesion. This process was repeated 5 times. The scheduled transplant EPCs were labeled with fluorescent cell marker (CM-DiI; Invitrogen,Carlsbad, USA) as previously described [28]. Dual antibody-coated EPC capture stents were then transported from the laboratory to the angiography suite in a sterile fashion. 


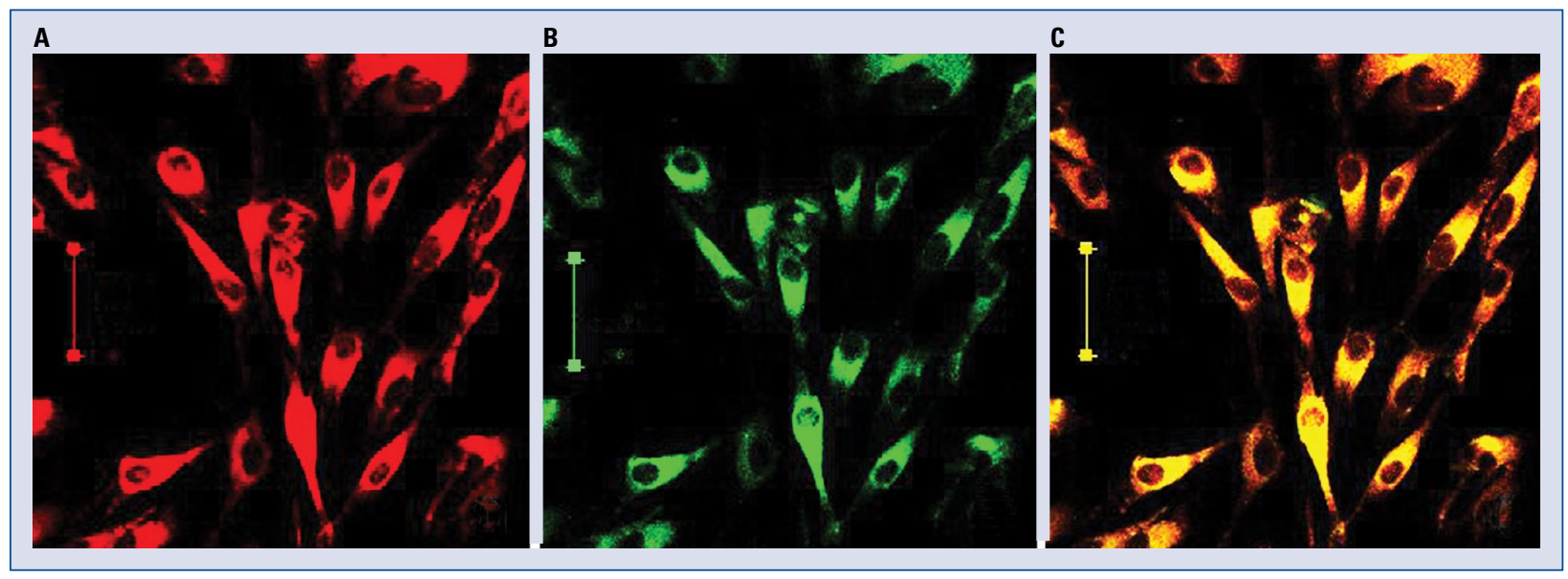

Figure 1. Inverted fluorescent microscopy images of endothelial progenitor cells (EPCs) that endocytosed Dil-Ac-LDL (A) and bound FITC-UEA-1 (B). The EPCs (overlay of A and B) are stained yellow (C). Scale bar $=50 \mu \mathrm{m}$.

In vivo stent placement and cell transplantation

Twenty male New Zealand white rabbits aged 2 months and established as atherosclerotic models were fed a high-lipid diet (normal diet with added $2 \%$ cholesterol, $5 \%$ fat, $7.5 \%$ yolk powder) at Southeast University Experimental Animal Center (Nanjing, China) for at least 1 month before stent deployment. The rabbits were injected intravenously with $10 \%$ bovine serum album (Biosharp, Roche, Shanghai, China) $25 \mathrm{mg} / \mathrm{kg}$ once daily for 3 consecutive days to induce an immune injury reaction [29]. Serum hypercholesterolemia was demonstrated via laboratory examination. The animals (mean weight, $3.1 \pm 0.3 \mathrm{~kg}$ ) were then randomly divided into one of two study groups: group $1(n=10)$ or group 2 (control group; $n=10)$.

On the angiography table, the animals were placed under general anesthesia with intravenous phenobarbital (Simcare, Beijing, China) $30 \mathrm{mg} / \mathrm{kg}$; local anesthesia with $2 \%$ lidocaine (China Otsuka Pharmaceutical Co., Ltd, Tianjin, China) $4.5 \mathrm{mg} / \mathrm{kg}$ was administered via subcutaneous infiltration before surgical incision. For all animals, patent airway and ventilation were maintained throughout the procedure, the circulatory systems were also supported with the administration of intravenous fluids.

Methods for creation of balloon injury and percutaneous stent placement in iliac arteries have been described previously [17]. In this study, a 4-French introducer sheath (Radifocus, Terumo, Japan) was surgically introduced into the right carotid artery and a 2.7 Fr microcatheter (Progreat, Terumo, Japan) was sub-selectively advanced into the lower abdominal aorta under fluoroscopic guidance (Zeego, Siemens, Forchheim, Germany). Post systemically heparinized with $200 \mathrm{IU} / \mathrm{kg}$ heparin sodium (Shanghai No.1 Biochemical Pharmacology Co. Ltd,Shanghai, China), maneuvers to create a balloon injury were performed 3 times with a $2.5 \mathrm{~mm} \times 15 \mathrm{~mm}$ balloon catheter (Star Progress Medical Ltd., Shanghai, China) at 6 atmospheres of pressure for $30 \mathrm{~s}$ in the right common external iliac artery. After the balloon injury was created, ten $3.0 \mathrm{~mm} \times 15 \mathrm{~mm}$ dual antibody-coated Sun BMS (group 1) or ten $3.0 \mathrm{~mm} \times 14 \mathrm{~mm}$ sirolimuseluting stents (Excel, JW Medical System, Weihai, China) (group 2) were randomly deployed at the dilated site of the right iliac arteries. Simultaneously, a mean amount of $5 \times 10^{6}$ EPCs labeled with DiI were continuously infused through the microcatheter just above the proximal edge of the stent, with a tourniquet placed on the ipsilateral thigh to block blood runoff for 2 min. After stent deployment, angiography was performed in all animals to exclude any acute thrombus formation.

\section{Postprocedural follow-up}

Penicillin 800,000 IU was administered intramuscularly daily for 3 days after the procedure. The animals were fed the high-lipid diet, provided with water ad libitum, and given oral acetylsalicylic acid $12.5 \mathrm{mg}$ once daily during follow-up. One month after the procedure, with the animals under general anesthesia, computed tomography angiography (CTA) was performed using $2.5 \mathrm{~mL} / \mathrm{kg}$ nonionic iodine medium (Omnipaque, Yangzi Pharmacy Ltd., Taizhou, China) via power injection through an ear edge vein; a dual-source CT SOMATOM 
Definition Flash scanner (Siemens AG, Forchheim, Germany) was used for all scans ( $140 \mathrm{KV}$ and $80 \mathrm{KV}$; automatically controlled mAs; 10 -s delay). CTA data were analyzed using vascular analysis software (Syngo.via, Siemens AG). After CTA was completed, a color Doppler duplex ultrasound examination (Philips HD7 XE, Amsterdam, the Netherlands) was performed to investigate target vessel preparation with the affected limb shaved. CTA and duplex ultrasound examinations were repeated 2 months thereafter before the animals were euthanized. The patency of the target vessel, minimum luminal diameter, and velocity of blood were recorded during these examinations.

\section{Restenosis definition}

Binary restenosis is defined as 50\% luminal narrowing on follow-up angiography [3]. For this study, ISR was determined by visual estimation and was defined as $>50 \%$ luminal narrowing within $5 \mathrm{~mm}$ proximal or distal to the stent. According to the current clinical literature, restenosis is identified as "very late" when it occurs 1 year after stent placement in humans [11]. For this animal study, the authors defined ISR as restenosis occurring 2 months after stent placement to account for the differences between rabbits and humans in life expectancies.

\section{Pathologic assessment}

The animals were euthanized with $5 \mathrm{~mL}$ intravenous $10 \% \mathrm{KCl}$ administered after 2 months of follow-up. Necropsy was performed immediately. The iliac artery with the stent was evaluated with gross photography and preserved for histologic assessment. Snap frozen slides were prepared in Optimum Cutting Temperature compound (Sakura Finetek Inc., Torrance, California, USA) to test the artery at the proximal and distal ends of the stent for DiI fluorescent stained cells. After tissue fixation in buffered $4 \%$ formaldehyde (Guduo Biotechnology, Shanghai, China) for $24 \mathrm{~h}$, the remaining tissue with stent in place was embedded in methyl methacrylate (Hubei Jusheng Bioscience, Wuhan, China) for hard tissue slicing. Tissue segments of proximal, central, and distal regions of the stent were then cut into 6 -micron sections with a diamond blade, and these segments were stained with hematoxylin-eosin. Immunohistochemistry staining was performed on separate sections using standard techniques to identify CD34 and VEGFR-2 phenotype expression.

The pseudointimal thickness from the stent struts to the lumen surface was measured at
6 equidistant points around the graft circumference (excluding the thrombus). The pseudointimal area and minimum luminal diameter were measured with microscopy using a LEICA DM LB2 microscope (Leica Microsystems Wetzlar GmbH, Wetzlar, Germany), and the morphometry was analyzed with software (LEICA Qwin v3).

\section{Statistical analysis}

Statistical analysis was performed using SPSS Version 19.0 (SPSS, Inc., Chicago, Illinois, USA). Continuous variables were expressed as mean \pm standard deviation (SD). An unpaired Student $t$ test was used to compare the EPC capture and DES groups. Categorical data were compared with a $\chi^{2}$ test or with the Fisher exact test when the expected cell value was $<5$. A p value $\leq 0.05$ (2-sided) was considered statistically significant.

\section{Results}

\section{Stent placement and}

\section{EPC local transplantation}

The technical success rates of stent placement and EPC transplantation were $100 \%$ for both groups. Anesthesia accident and cardiac arrest cases $(n=2)$ that occurred during the preliminary study were excluded from review. No cases of acute thrombosis, stent malposition, or infection occurred during the procedures.

\section{Follow-up data: laboratory and imaging}

After consuming a high-lipid diet for 1 month before stent placement, the rabbits had a mean serum cholesterol level of $37.9 \pm 1.1 \mathrm{mmol} / \mathrm{L}$, triglyceride level of $3.4 \pm 2.3 \mathrm{mmol} / \mathrm{L}$, and lowdensity lipoprotein cholesterol level of $26.1 \pm 2.3$ $\mathrm{mmol} / \mathrm{L}$, nearly 2 - to 8 -fold higher than the upper limits of normal values. Fatty liver, arterial atherosclerotic plaque, and foam cells were detected on microscopy examination.

One month after stent placement, CTA demonstrated that all stents were patent in group 1; color Doppler sonography demonstrated 1 case of distal end ISR in group 1, although this case appeared normal on CTA. In Group 2, 1 case of proximal restenosis and 1 case of total occlusion were detected by both CTA and ultrasound, 8 stents were patent. Two months after stent placement, CTA demonstrated that 9 stents were patent in group 1, with 1 distal end ISR; in group 2, there were 3 cases of ISR and 1 case of occlusion (Fig. 2), 6 stents were patent. Therefore, the ISR rate was $1 / 10$ in group 1 and $4 / 10$ in group $2(\mathrm{p}=0.18)$. 


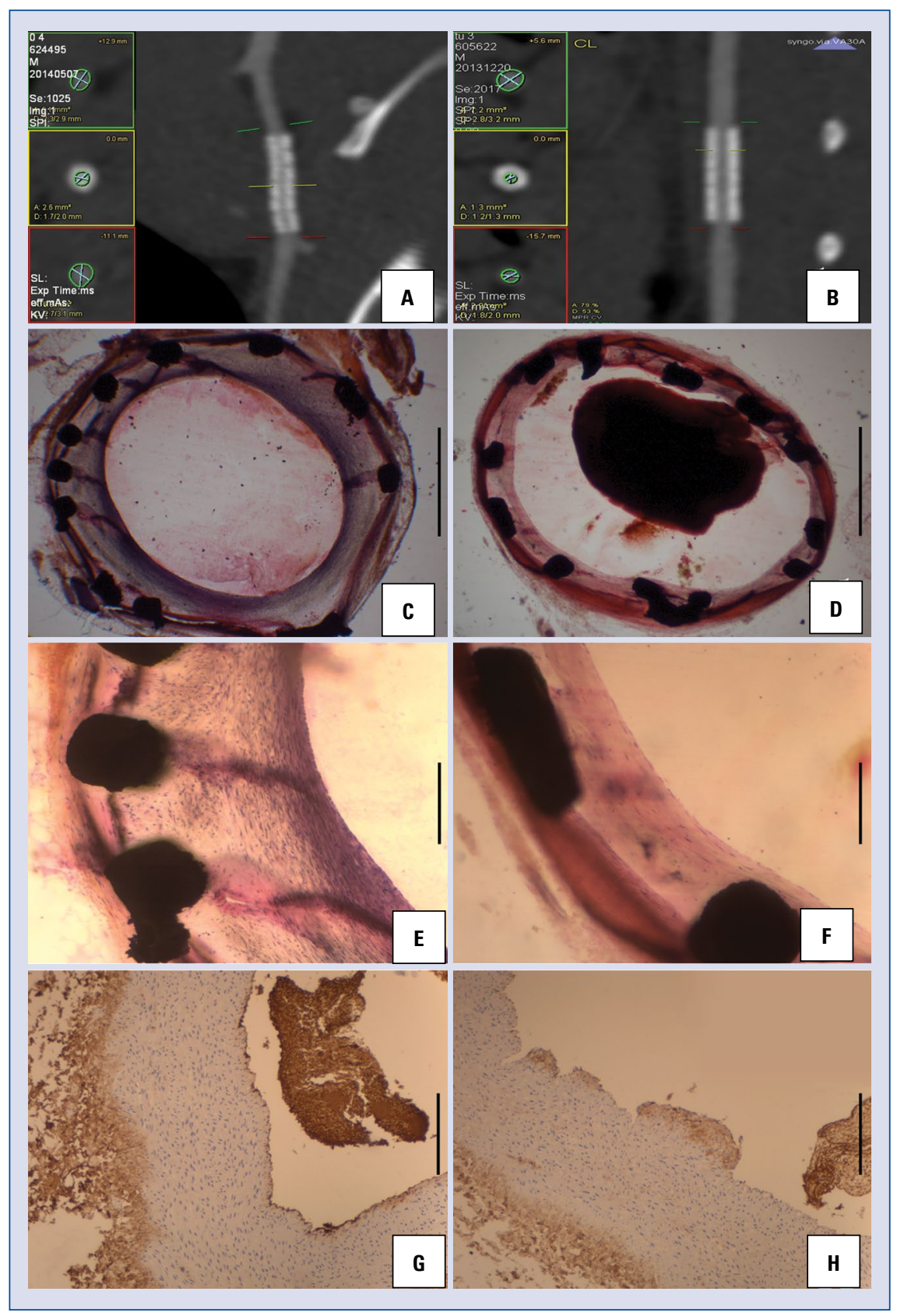

Figure 2. Multiplanar reformatted computed tomography angiography images of endothelial progenitor cells (EPCs) capture stent in group 1 (A) and drug-eluting stent in group 2 (B) after 2 months of follow-up. Microscopy of hematoxylin-eosin staining in group 1 (C, E) and group $2(\mathbf{D}, \mathbf{F})$ in hard tissue slices. Neointimal hyperplasia was markedly thicker in group 1 than in group 2, and a red thrombus was revealed in the stent lumen in group 2. Immunohistochemical microscopy revealed CD 34+ staining cells (brown) closely lining the endothelium in group 1 (G) but loosely lining the endothelium in group $2(\mathbf{H})$. Scale bar $=1000 \mu \mathrm{m}$ in images $C$ and $D$; scale bar $=200$ um in images $E, F, G$, and $H$.

Although the in-stent minimal diameter and luminal area in group 2 trended somewhat smaller than the in-stent minimal diameter and luminal area in group 1, these differences were not statistically significant $(\mathrm{p}>0.05$; Table 1$)$.

As measured by duplex ultrasound, the velocity of blood in the stent was $61.2 \pm 14.4 \mathrm{~cm} / \mathrm{s}$ in group 1 vs. $74.4 \pm 9.0 \mathrm{~cm} / \mathrm{s}$ in group $2(\mathrm{p}>0.05)$, and the minimal diameter of the stent was $1.90 \pm$ $\pm 0.10 \mathrm{~mm}$ in group 1 vs. $1.70 \pm 0.30 \mathrm{~mm}$ in group $2(\mathrm{p}>0.05)$.

\section{Pathologic analysis of stent segments}

DiI-positive cells were extensively detected in samples of the luminal side of the artery from group 1, indicating that the transplanted EPCs 
Table 1. Computed tomography angiography data of different site stent luminal diameter and area.

\begin{tabular}{lllllllll}
\hline \multirow{2}{*}{ Group } & \multicolumn{2}{c}{ Luminal diameter $[\mathrm{cm}]$} & & \multicolumn{3}{c}{ Luminal area $\left[\mathrm{cm}^{2}\right]$} \\
\cline { 2 - 3 } & Proximal & Minimal & Distal & & Proximal & Minimal* & Distal \\
\hline 1 & $2.38 \pm 0.39$ & $1.85 \pm 0.15$ & $2.30 \pm 0.50$ & & $5.10 \pm 1.43$ & $3.05 \pm 0.45$ & $4.83 \pm 1.97$ \\
2 & $2.43 \pm 0.49$ & $1.50 \pm 0.20$ & $2.23 \pm 0.78$ & & $5.50 \pm 2.13$ & $1.97 \pm 0.44$ & $4.80 \pm 3.20$ \\
\hline
\end{tabular}

${ }^{*} p<0.05$. Group $1-$ anti-CD34, anti-VEGFR2 dual antibody coated endothelial progenitor cell capture stent group, Group 2 - sirolimus-eluting stent group

Table 2. Morphometry analysis of samples from group 1 and group 2.

\begin{tabular}{lccc}
\hline Group & $\begin{array}{c}\text { Minimum luminal } \\
\text { diameter [mm] }\end{array}$ & $\begin{array}{c}\text { Neo-intimal hyperplasia } \\
\text { thickness [mm]* }\end{array}$ & $\begin{array}{c}\text { Intimal hyperplasia } \\
{\text { area }\left[\mathrm{mm}^{2}\right]^{*}}^{*}\end{array}$ \\
\hline 1 & $2.28 \pm 0.38$ & $0.21 \pm 0.09$ & $1.82 \pm 0.52$ \\
2 & $2.68 \pm 0.12$ & $0.11 \pm 0.07$ & $0.92 \pm 0.52$ \\
\hline
\end{tabular}

*p $<0.05$. Group 1 - anti-CD34, anti-VEGFR2 dual antibody coated endothelial progenitor cell capture stent group, Group 2 - sirolimus-eluting stent group

grew and differentiated to endothelial cells among the pseudointima layer. DiI-positive cells were observed sporadically in samples from group 2.

Microscopy demonstrated integrity of the endothelium layer and exuberant neointimal hyperplasia in group 1. CD34 and VEGFR-2 were positively expressed on the luminal side in group 1 . In group 2, almost no intact monolayer endothelium formation was observed, but 3 red thrombi were detected in the stent lumen (Fig. 2). Morphometry demonstrated that the thickness of the neointima in group 1 was significantly greater than in group 2 $(0.21 \pm 0.09 \mathrm{~mm}$ vs. $0.11 \pm 0.07 \mathrm{~mm} ; \mathrm{p}<0.05)$. The neointimal area was significantly larger in group $1\left(1.82 \pm 0.52 \mathrm{~mm}^{2}\right.$ vs. $0.92 \pm 0.52 \mathrm{~mm}^{2}$, $\mathrm{p}<0.05)$, and the minimum luminal diameter was significantly smaller in group 1 (excluding thrombus, $2.28 \pm 0.38 \mathrm{~mm}$ vs. $2.68 \pm 0.12 \mathrm{~mm}$, $\mathrm{p}<0.05)$ (Table 2).

\section{Discussion}

In this study, transplanted EPCs could be detected on the stent luminal side and were found to have differentiated to functional endothelial cells in vivo in the EPC capture stent group. These results suggest that it is feasible to use a dual antibodycoated EPC capture stent combined with local EPC delivery to achieve rapid re-endothelialization in vivo. A nonsignificant trend toward a reduced rate of late-stage ISR (achieved via inhibition of in-stent thrombosis rather than via reduction of neointimal hyperplasia) in the EPC capture stent group was also noted.

These results differ from those seen in some previous animal studies [17-19]. The authors of these studies concluded that recruiting circulation EPCs on the stent may promote re-endothelialization and inhibit neointimal hyperplasia via the same process. They suggest that the integral endothelium seems not only to prevent neointimal hyperplasia but also to prompt the normal healing process and decrease the rate of acute and chronic thrombosis. Conversely, clinical studies with the Genous R stent and the current study failed to demonstrate this inhibition of neointimal hyperplasia. One possible explanation for this difference is that recruited circulation CD34 EPCs may also transdifferentiate to SMCs under certain conditions (e.g., in the presence of transforming growth factor-beta) [30], suggesting that the specific microenvironment for EPCs determines their fate and the effects of cellular therapy. Therefore, more efforts are needed to improve the EPC microenvironment, which can enhance therapeutic potential [31].

Injury of the endothelium is the first step in atherosclerosis and is the predisposing factor for the occurrence of ISR. Recent studies have suggested that EPCs can treat regional ischemia or injured vessels by prompting angiogenesis [31, 32]. These EPCs, which can be easily harvested from peripheral blood, bone marrow, or the umbilical vein, differentiate into mature endothelial cells in vivo. Previous work demonstrated that 
EPCs can be successfully seeded on BMS struts in vitro and in vivo, and this EPC seeding was found to improve patency in transjugular intrahepatic portosystemic shunts in a porcine model [33, 34]. According to available research, in patients with severe atherosclerosis, diabetes, history of heavy smoking, hypercholesterolemia, or older age, there is an extreme paucity of EPCs available in the circulation, and the function of the EPCs that are present is compromised to a certain extent. Local transplantation of allogenous EPCs is a potential option to address this issue [35]. In this study, two different modalities of cell therapy (implanting EPCs and using specific antibody-coated stentbased therapy) were included in an attempt to recruit EPCs. The number of DiI-positive cells from the intima layer was markedly higher in the EPC capture stent group than in the DES group. These results suggest that locally transplanted EPCs are effectively captured by dual antibody-coated stent struts, homing to the wounded site and incorporating into the intima components.

Drug-eluting stent inhibit not only SMC proliferation but also endothelial cell growth, which may explain why no intact endothelium was detected in the DES group in this study. The higher total ISR rate in the DES group was likely due to delayed re-endothelialization, inadequate antibiotic prophylaxis, and invasive surgical protocol [2, 16, 29].

Restenotic and thrombotic processes may occasionally coexist, especially in cases characterized by neointimal hyperplasia plus focal thrombosis inside the stent $[3,36,37]$. The "thromborestenosis" phenomenon is a theory describing how chronic thrombus formation may play an integral role in the development of ISR [38]. Recently, Alfonso et al. suggested that the substrate of ISR encompasses a pathologic spectrum ranging from SMC proliferation to neoatherosclerosis [39, 40]. Among currently available therapeutic modalities for these patients, DES and drug-eluting balloons provide the best clinical and angiographic results in patients with ISR. The investigators suggested that everolimus-eluting stents should be considered the first-line therapy of choice in these challenging scenarios. However, to prevent a primary episode of ISR, combining EPC-capturing technology with drug-eluting technology may be a promising approach for improving clinical outcomes in the future [31]. Further studies are needed to explore this potential approach. Further studies are also needed to determine whether a dual antibody-coated EPC capture stent has a synergistic effect or whether it is more effective than a single antibody- or genecoated stent.

\section{Limitations of the study}

This study had several limitations. First, because the stent was placed in a peripheral rather than a coronary conduit, the rate and mechanism of ISR may not have been identical across cases. Second, the small sample size limited the statistical power of the study. Third, using only male animals may have resulted in sex selection bias, potentially influencing outcomes. Fourth, premature discontinuation of dual antiplatelet therapy (without the use of clopidogrel and cilostazol) varies across clinical settings, which may affect the interpretation of these results. Finally, previous studies have shown that DES is superior to BMS in preventing in-stent stenosis in most clinical settings, and EPC-coated stents have been demonstrated to be more effective than BMS in inhibiting neointima hyperplasia [17-19, 41, 42]. Therefore in this experimental study, the authors directly compared the modified EPC-capture stent with DES; further studies incorporating a larger sample size and with a more robust design (such as including a BMS control arm) are needed.

\section{Conclusions}

Use of a dual antibody-coated EPC capture stent concomitant with local EPC transplant decreased the rate of ISR in vivo when compared with DES in an atherosclerotic animal model. This reduced ISR with the use of EPC capture stents may be achieved through a reduction in the in-stent thrombosis rate rather than through inhibition of neointimal hyperplasia.

\section{Acknowledgements}

The authors thank Dr. Douglas Coldwell for his kind manuscript preparation, Drs. Yi-Yao Cui and Hui Yu for their technical assistance. The authors also pay great gratitude to Jiangsu Key Laboratory of Molecular Imaging and Functional Imaging, Southeast University for the support of cell culture.

Funding: This study is supported by Natural Science Foundation of Jiangsu Province, China (BK2012589)

\section{Conflict of interest: None declared}




\section{References}

1. Mozaffarian D, Benjamin EJ, Go AS, et al. American Heart Association Statistics Committee and Stroke Statistics Subcommittee. Heart disease and stroke statistics: 2015 update: a report from the American Heart Association. Circulation. 2015; 131(4): e29-322, doi: 10.1161/CIR.0000000000000152, indexed in Pubmed: 25520374.

2. Serruys PW, Kutryk MJB, Ong ATL. Coronary-artery stents. NEngl J Med. 2006; 354(5): 483-495, doi: 10.1056/NEJMra051091, indexed in Pubmed: 16452560.

3. Dangas GD, Claessen BE, Caixeta A, et al. In-stent restenosis in the drug-eluting stent era. J Am Coll Cardiol. 2010; 56(23): 1897-1907, doi: 10.1016/j.jacc.2010.07.028, indexed in Pubmed: 21109112.

4. Cosgrave J, Agostoni P, Ge L, et al. Clinical outcome following aleatory implantation of paclitaxel-eluting or sirolimus-eluting stents in complex coronary lesions. Am J Cardiol. 2005; 96(12): 1663-1668, doi: 10.1016/j.amjcard.2005.07.082, indexed in Pubmed: 16360354.

5. Stone GW, Ellis SG, Cannon L, et al. TAXUS V Investigators. Comparison of a polymer-based paclitaxel-eluting stent with a bare metal stent in patients with complex coronary artery disease: a randomized controlled trial. JAMA. 2005; 294(10): 1215-1223, doi: 10.1001/jama.294.10.1215, indexed in Pubmed: 16160130.

6. Cassese S, Byrne RA, Tada T, et al. Incidence and predictors of restenosis after coronary stenting in 10004 patients with surveillance angiography. Heart. 2014; 100(2): 153-159, doi: 10.1136/ heartjnl-2013-304933, indexed in Pubmed: 24270744.

7. Sun Y, Li L, Su Q, et al. Comparative efficacy and safety of drug-eluting stent and conventional therapies in coronary heart disease patients with in-stent restenosis: a meta-analysis. Cell Biochem Biophys. 2014; 68(1): 211-229, doi: 10.1007/s12013013-9692-7, indexed in Pubmed: 23784750.

8. Unverdorben M, Vallbracht C, Cremers B, et al. Paclitaxel-coated balloon catheter versus paclitaxel-coated stent for the treatment of coronary in-stent restenosis. Circulation. 2009; 119(23): 2986-2994, doi: 10.1161/CIRCULATIONAHA.108.839282, indexed in Pubmed: 19487593.

9. Holmes DR, Kereiakes DJ, Garg S, et al. Stent thrombosis. J Am Coll Cardiol. 2010; 56(17): 1357-1365, doi: 10.1016/j. jacc.2010.07.016, indexed in Pubmed: 20946992.

10. Tsigkas GG, Karantalis V, Hahalis G, et al. Stent restenosis, pathophysiology and treatment options: a 2010 update. Hellenic J Cardiol. 2011; 52(2): 149-157, indexed in Pubmed: 21478125.

11. Collins MJ, Li X, Lv W, et al. Therapeutic strategies to combat neointimal hyperplasia in vascular grafts. Expert Rev Cardiovasc Ther. 2012; 10(5): 635-647, doi: 10.1586/erc.12.33, indexed in Pubmed: 22651839.

12. Byrne RA, Neumann FJ, Mehilli J, et al. ISAR-DESIRE 3 investigators. Paclitaxel-eluting balloons, paclitaxel-eluting stents, and balloon angioplasty in patients with restenosis after implantation of a drug-eluting stent (ISAR-DESIRE 3): a randomised, open-label trial. Lancet. 2013; 381(9865): 461-467, doi: 10.1016/ S0140-6736(12)61964-3, indexed in Pubmed: 23206837.

13. Razavi MK, Mustapha JA, Miller LE. Contemporary systematic review and meta-analysis of early outcomes with percutaneous treatment for infrapopliteal atherosclerotic disease. J Vasc Interv Radiol. 2014; 25(10): 1489-96, 1496.e1, doi: 10.1016/j. jvir.2014.06.018, indexed in Pubmed: 25130307.
14. Bosiers M, Deloose K, Callaert J, et al. Superiority of stent-grafts for in-stent restenosis in the superficial femoral artery: twelvemonth results from a multicenter randomized trial. J Endovasc Ther. 2015; 22(1): 1-10, doi: 10.1177/1526602814564385, indexed in Pubmed: 25775672.

15. Dippel EJ, Makam P, Kovach R, et al. EXCITE ISR Investigators. Randomized controlled study of excimer laser atherectomy for treatment of femoropopliteal in-stent restenosis: initial results from the EXCITE ISR trial (EXCImer Laser Randomized Controlled Study for Treatment of FemoropopliTEal InStent Restenosis). JACC Cardiovasc Interv. 2015; 8(1 Pt A): 92-101, doi: 10.1016/j.jcin.2014.09.009, indexed in Pubmed: 25499305.

16. Aoki J, Serruys PW, van Beusekom H, et al. Endothelial progenitor cell capture by stents coated with antibody against CD34: the HEALING-FIM (Healthy Endothelial Accelerated Lining Inhibits Neointimal Growth-First In Man) Registry. J Am Coll Cardiol. 2005; 45(10): 1574-1579, doi: 10.1016/j.jacc.2005.01.048, indexed in Pubmed: 15893169.

17. Sharif F, Hynes SO, Cooney R, et al. Gene-eluting stents: adenovirus-mediated delivery of eNOS to the blood vessel wall accelerates re-endothelialization and inhibits restenosis. Mol Ther. 2008; 16(10): 1674-1680, doi: 10.1038/mt.2008.165, indexed in Pubmed: 18714308.

18. Walter DH, Cejna M, Diaz-Sandoval L, et al. Local gene transfer of phVEGF-2 plasmid by gene-eluting stents: an alternative strategy for inhibition of restenosis. Circulation. 2004; 110(1): 36-45, doi: 10.1161/01.CIR.0000133324.38115.0A, indexed in Pubmed: 15210598.

19. Blindt R, Vogt F, Astafieva I, et al. A novel drug-eluting stent coated with an integrin-binding cyclic Arg-Gly-Asp peptide inhibits neointimal hyperplasia by recruiting endothelial progenitor cells. J Am Coll Cardiol. 2006; 47(9): 1786-1795, doi: 10.1016/j. jacc.2005.11.081, indexed in Pubmed: 16682302.

20. Strehlow K, Werner N, Berweiler J, et al. Estrogen increases bone marrow-derived endothelial progenitor cell production and diminishes neointima formation. Circulation. 2003; 107(24): 3059-3065, doi: 10.1161/01.CIR.0000077911.81151.30, indexed in Pubmed: 12810616.

21. Egashira K, Nakano K, Ohtani K, et al. Local delivery of antimonocyte chemoattractant protein-1 by gene-eluting stents attenuates in-stent stenosis in rabbits and monkeys. Arterioscler Thromb Vasc Biol. 2007; 27(12): 2563-2568, doi: 10.1161/ATVBAHA.107.154609, indexed in Pubmed: 17885211.

22. Garg R, Tellez A, Alviar C, et al. The effect of percutaneous coronary intervention on inflammatory response and endothelial progenitor cell recruitment. Catheter Cardiovasc Interv. 2008; 72(2): 205-209, doi: 10.1002/ccd.21611, indexed in Pubmed: 18651648 .

23. Miglionico M, Patti G, D’Ambrosio A, et al. Percutaneous coronary intervention utilizing a new endothelial progenitor cells antibody-coated stent: a prospective single-center registry in high-risk patients. Catheter Cardiovasc Interv. 2008; 71(5): 600-604, doi: 10.1002/ccd.21437, indexed in Pubmed: 18360849.

24. den Dekker WK, Houtgraaf JH, Onuma Y, et al. Final results of the HEALING IIB trial to evaluate a bio-engineered CD34 antibody coated stent (Genous ${ }^{\mathrm{TM}}$ Stent) designed to promote vascular healing by capture of circulating endothelial progenitor cells in CAD patients. Atherosclerosis. 2011; 219(1): 245-252, doi: 10.1016/j.atherosclerosis.2011.06.032, indexed in Pubmed: 21763653. 
25. Klomp M, Damman P, Beijk MAM, et al. Applying the National Institute for Clinical Excellence criteria to patients treated with the Genous $^{\mathrm{TM}}$ Bio-engineered R stent ${ }^{\mathrm{TM}}$ : a sub-study of the e-HEALING (Healthy Endothelial Accelerated Lining Inhibits Neointimal Growth) worldwide registry. Heart Vessels. 2012; 27(4): 360-369, doi: 10.1007/s00380-011-0167-8, indexed in Pubmed: 21725668.

26. Cassese S, Galasso G, Sciahbasi A, et al. Antiplatelet theRapy after Genous EPC-capturing coroNary stenT implantatiOn: the ARGENTO study: a prospective, multicenter registry. Int J Cardiol. 2013; 167(3): 757-761, doi: 10.1016/j.ijcard.2012.03.052, indexed in Pubmed: 22459371.

27. Mai XL, Ma ZL, Sun JH, et al. Assessments of proliferation capacity and viability of New Zealand rabbit peripheral blood endothelial progenitor cells labeled with superparamagnetic particles. Cell Transplant. 2009; 18(2): 171-181, indexed in Pubmed: 19499705.

28. Li Na, Yang H, Lu L, et al. Comparison of the labeling efficiency of BrdU, DiI and FISH labeling techniques in bone marrow stromal cells. Brain Res. 2008; 1215: 11-19, doi: 10.1016/j.brainres.2007.09.095, indexed in Pubmed: 18468584.

29. Falk E. Pathogenesis of Atherosclerosis. J Am Coll Cardiol. 2006; 47(8 Suppl): C7-C12, doi: 10.1016/j.jacc.2005.09.068.

30. Imamura $\mathrm{H}$, Ohta $\mathrm{T}$, Tsunetoshi $\mathrm{K}$, et al. Transdifferentiation of bone marrow-derived endothelial progenitor cells into the smooth muscle cell lineage mediated by tansforming growth factor-beta1. Atherosclerosis. 2010; 211(1): 114-121, doi: 10.1016/j. atherosclerosis.2010.02.040, indexed in Pubmed: 20303084.

31. Xu BY, Xiang MX, Wang Ja. Endothelial Progenitor Cells and In-stent Restenosis. Curr Stem Cell Res Ther. 2015; 10(4): 364-371, indexed in Pubmed: 25654305.

32. Asahara T, Murohara T, Sullivan A, et al. Isolation of putative progenitor endothelial cells for angiogenesis. Science. 1997; 275(5302): 964-967, indexed in Pubmed: 9020076.

33. Shi HJ, Cao AH, Chen J, et al. Transjugular intrahepatic portosystemic shunt with an autologous endothelial progenitor cell seeded stent: a porcine model. Acad Radiol. 2010; 17(3): 358-367, doi: 10.1016/j.acra.2009.10.007, indexed in Pubmed: 19962914.
34. Shi HJ, Cao AH, Teng GJ. Seeding endothelial progenitor cells on a self-expanding metal stent: an in vitro study. J Vasc Interv Radiol. 2010; 21(7): 1061-1065, doi: 10.1016/j.jvir.2010.03.019, indexed in Pubmed: 20610181.

35. Marsboom G, Janssens S. Endothelial progenitor cells: new perspectives and applications in cardiovascular therapies. Expert Rev Cardiovasc Ther. 2008; 6(5): 687-701, doi: 10.1586/14779072.6.5.687, indexed in Pubmed: 18510485.

36. Centemero MP, Stadler JR. Stent thrombosis: an overview. Expert Rev Cardiovasc Ther. 2012; 10(5): 599-615, doi: 10.1586/ erc.12.38, indexed in Pubmed: 22651836.

37. Kim MS, Dean LS. In-stent restenosis. Cardiovasc Ther. 2011; 29(3): 190-198, doi: 10.1111/j.1755-5922.2010.00155.x, indexed in Pubmed: 20406239.

38. Farooq V, Gogas BD, Serruys PW. Restenosis: delineating the numerous causes of drug-eluting stent restenosis. Circ Cardiovasc Interv. 2011; 4(2): 195-205, doi: 10.1161/CIRCINTERVENTIONS.110.959882, indexed in Pubmed: 21505166.

39. Fusaro M, Cassese S, Ndrepepa G, et al. Drug-eluting stents for revascularization of infrapopliteal arteries: updated metaanalysis of randomized trials. JACC Cardiovasc Interv. 2013; 6(12): 1284-1293, doi: 10.1016/j.jcin.2013.08.007, indexed in Pubmed: 24355118.

40. Alfonso F, Pérez-Vizcayno M, Cárdenas A, et al. A prospective randomized trial of Drug-Eluting balloons versus everolimuseluting stents in patients with in-stent restenosis of drug-eluting stents. J Am Coll Cardiol. 2015; 66(1): 23-33, doi: 10.1016/j. jacc.2015.04.063.

41. Spaulding C, Daemen J, Boersma E, et al. A pooled analysis of data comparing sirolimus-eluting stents with bare-metal stents. N Engl J Med. 2007; 356(10): 989-997, doi: 10.1056/ NEJMoa066633, indexed in Pubmed: 17296825.

42. Kaiser C, Galatius S, Erne P, et al. BASKET-PROVE Study Group. Drug-eluting versus bare-metal stents in large coronary arteries. N Engl J Med. 2010; 363(24): 2310-2319, doi: 10.1056/ NEJMoa1009406, indexed in Pubmed: 21080780. 